\title{
UK's plan to build community care centres for Ebola patients is questioned
}

\author{
Anne Gulland
}

London

MPs have heard doubts about aspects of the UK government's strategy to curb the Ebola epidemic in Sierra Leone.

In evidence presented to the parliamentary international development committee on 11 November two representatives from Médecins Sans Frontières, the charity at the forefront of the response to the Ebola outbreak in west Africa, questioned the UK government's plans to build 200 community care centres.

Andre Heller Perache, head of UK programmes for the charity, said it did not want to stand in the way of "fresh strategies" and "creative thinking." But he said that existing holding and transit centres for patients with Ebola virus disease were overcrowded and needed support. "The way [the community care centres are] operating, the way they're putting responsibilities on the community, and the way they're designed is not something MSF [Médecins Sans Frontières] is behind at this point."

Javid Abdelmoneim is an emergency medicine doctor in London who recently returned from Sierra Leone, where he volunteered with the charity. He said, "Why build 200 new centres when there are holding centres already that need input and the full logistical back up: laboratory, safe burial, disposal of materials, food. Why not get them working well? They are close to the patients already. To me that would be a much more practical solution."

However, John Edmunds, an epidemiologist at the London School of Hygiene and Tropical Medicine, said that the Department for International Development's strategy of developing smaller community centres and the six larger treatment centres, the first of which opened last week, was the right one.

"We need to have facilities closer to the patients. This idea of transporting patients for hours in the back of uncomfortable ambulances is both dangerous and not conducive to patients coming forward to getting early treatment," he said.

The latest figures on Ebola from the World Health Organization, dated 7 November, showed 13268 cases of the disease, including 4960 deaths. The Sierra Leone ministry of health and sanitation reported a spike in the number of cases over the weekend, with 111 cases on 9 November-the largest daily total since August.

The committee heard praise for the department's current efforts but criticism of its failure to respond until August, five months after Médecins Sans Frontières first called international attention to the outbreak. Heller Perache said that the charity's call for a military response to the crisis back in September had not been fully heeded.

International development secretary Justine Greening, who gave evidence to the committee separately, said that alongside the six larger Ebola treatment centres, which would have capacity for a total of 700 beds, the UK was working on bringing existing buildings into use. "We have also done a lot of work to enable quick availability of existing beds that's sometimes been done by bringing existing buildings into service, sometimes by helping existing hospitals expand," she said.

When asked how the international community, including WHO, could have responded better to the outbreak Greening said that now was not the time to look at mistakes but to focus on the epidemic itself. She told the committee that the international response had improved and that donors felt more confident in pledging help now that the UK had taken a lead in developing a strategy for Sierra Leone.

She said that 200 Norwegian healthcare workers were to help run a treatment centre in Moyamba, and Australia and New Zealand had pledged to send healthcare workers. Prime Minister David Cameron would be calling for more help at next week's G20 meeting in Brisbane, she added.

Access all of The BMJs content on the ongoing Ebola outbreak at thebmj.com/ebola.

Cite this as: BMJ 2014;349:96788

๑ BMJ Publishing Group Ltd 2014 